\title{
Light-stimulated dephosphorylation of the BiP-like protein, SmicHSP75 (SBiP1) from Symbiodinium microadriaticum is inhibited by elevated but not low temperature and suggests regulation of the chaperone function
}

\author{
Raúl Eduardo Castillo-Medina, Tania Islas-Flores and Marco A. Villanueva $\bowtie$ \\ Instituto de Ciencias del Mar y Limnología, Unidad Académica de Sistemas Arrecifales, Universidad Nacional Autónoma de México-UNAM, \\ Prolongación Avenida Niños Héroes S/N, Puerto Morelos, Quintana Roo 77580, México
}

Specific phosphorylation/dephosphorylation processes are fundamental for the transduction of external stimuli into physiological responses. A few of these processes appear to be modulated by light in cultured Symbiodinium microadriaticum since the BiP-like protein SmichSP75 undergoes threonine dephosphorylation upon light stimuli. Several isoforms of the protein are encoded in the $S$. microadriaticum genome and thus, we identified and heterologously expressed a specific sequence corresponding to the previously identified SmicHSP75 isoform to obtain a highly specific antibody. We then determined by western blot analysis, that the detected light-stimulated changes in SmicHSP75 threonine phosphorylation were not due to changes in the protein expression and explored further the effect of lower than normal and higher stressful temperature, on the phosphorylation levels of the protein. Upon long-term (12 h) exposure of the cells to the low temperature of $21^{\circ} \mathrm{C}$ under darkness, the protein was found significantly phosphorylated; however, light exposure for $30 \mathrm{~min}$ caused a dephosphorylation effect like the $26^{\circ} \mathrm{C}$ control treatment. On the other hand, in cells exposed to $32^{\circ} \mathrm{C}$ for $12 \mathrm{~h}$ under darkness, the highly Thr-phosphorylated SmicHSP75 was converted to a low-level phosphorylated protein. Likewise, short term $(30 \mathrm{~min})$ exposure to $32^{\circ} \mathrm{C}$ under dark conditions caused dephosphorylation of the protein, similar to what was observed upon long-term exposure to $32^{\circ} \mathrm{C}$ and upon light stimulation of cells under the normal temperature of $26^{\circ} \mathrm{C}$. These data suggested activation/inactivation of the chaperone function of SmicHSP75 by regulation of its Thr phosphorylation levels under heat stress conditions in Symbiodinium microadriaticum, independent of changes in protein expression.

Keywords: BiP-like protein; heat shock; light stimulation; phosphorylation; stress; Symbiodinium microadriaticum

Received: 11 August, 2021; revised: 29 September, 2021; accepted: 18 October, 2021; available on-line: 11 February, 2022

凶e-mail: marco@cmarl.unam.mx

Acknowledgements of Financial Support: Work financed by grants 285802 from the National Council of Science and Technology-México (CONACYT) and IN203718 from PAPIIT-UNAM. RC-M was supported by fellowship 255464 from CONACyT.

Abbreviations: PBS, phosphate-buffered saline; TBS, Tris-buffered saline; SDS-PAGE, sodium dodecyl sulfate-polyacrylamide gel electrophoresis; TX-100, Triton X-100

\section{INTRODUCTION}

Symbiodinium microadriaticum are photosynthetic dinoflagellates usually found in mutualistic symbiosis with the jellyfish Cassiopea xamachana. They can also live freely in the water column and therefore, are amenable for in vitro culture. Under either condition, they are subjected to the stress imposed by global warming. In particular, members of the Symbiodiniaceae family in mutualistic symbioses with reef forming corals, suffer when the sea water temperature elevates and the symbiotic association is lost and, in turn, the coral polyps die leaving their calcareous skeletons in a condition known as coral bleaching (Hoegh-Guldberg et al., 2007). Numerous reports have documented the negative effects of heat stress on these cells, especially those causing perturbations of their photosynthetic machinery (Iglesias-Prieto et al., 1992; Warner et al., 1999; Takahashi et al., 2004). For example, it is known that in corals exposed to light, a moderate increase of temperature could induce coral bleaching through photobleaching of algal pigments and the primary target for damage was the photosystem II (PSII) (Takahashi et al., 2004). Heat-dependent photoinhibition was ascribed to inhibition of the repair of photodamaged PSII. Thus, the loss of efficiency of the photosynthesis repair machinery directly affected the bleaching susceptibility of coral species under high seawater temperature (Takahashi et al., 2004). In fact, earlier studies indicated that severe damage to PSII in remaining symbionts from bleaching corals showed a direct correlation between loss in PSII activity and a significant decline in the D1 reaction center protein of PSII (Warner et al., 1999). This was further demonstrated in laboratory experiments using temperature-sensitive and temperature-tolerant cultured symbiotic dinoflagellates. It was concluded that the perturbation of the PSII protein turnover rates during photoinhibition at elevated temperatures underlies the physiological collapse of symbionts in corals susceptible to heat-induced bleaching (Warner et al., 1999). In addition to elevated temperature stress, light exposure itself in the form of solar irradiance has been reported as a secondary factor associated with coral bleaching (Lesser \& Farrell, 2004). Studies on the coral Montastraea (Orbicella) faveolata showed that exposure to high solar radiation and elevated temperatures resulted in a decreased efficiency of PSII and the concentration of D1 protein was significantly lower in high light when it was compared to low light treatments. The bleaching effect was also correlated with a possible increase in reactive oxygen spe- 
cies (ROS), thus linking light irradiance with ROS generation (Lesser \& Farrell, 2004).

We have previously reported the presence of a BiPlike $75 \mathrm{kDa}$ protein of the heat shock protein 70 (HSP70) family in $S$. microadriaticum (initially named SmicHSP75), based on de novo partial peptide sequence identity, which matched Cryptecodinium cohnii and Oryza sativa BiP sequences. BiP's are chaperones localized in the endoplasmic reticulum (RE), where they assist the folding and assembly of newly synthesized proteins. They also bind to misfolded, underglycosylated or unassembled proteins (Otero et al., 2010). On the other hand, BiP's also participate in the unfolded protein response (UPR) process as a protective mechanism against stress events (Lewy et al., 2017). These proteins are regulated at the transcriptional level by transcription factors (Anckar \& Sistonen, 2011), but they can also be regulated by several post-translational modifications that include AMPylation, ADP-ribosylation, methylation, ubiquitination, and acetylation. In addition, controlling BiP activity through phosphorylation appears to be a commonly used mechanism used by eukaryotic cells (Nitika et al., 2020). It was first reported that phosphorylated $\mathrm{BiP}$ was associated to oligomeric forms and that they probably represented an inactive state of BiP (Hendershot et al., 1988). Afterward, it was observed that phosphorylation decreased with thermal stress or when cells were exposed to cycloheximide or tunicamycin, inhibitors of protein synthesis or of N-glycosylation bonds of nascent proteins in the ER, respectively (Freiden et al., 1992; Satoh et al., 1993; DíazTroya et al., 2011). Overall, the most accepted model proposes that phosphorylation promotes an inactive form of $\mathrm{BiP}$ and that stress events or increases in protein synthesis in the ER regulate the activation of $\mathrm{BiP}$ through its dephosphorylation, allowing BiP-client complex formation (Crespo, 2012; Pérez-Pérez et al., 2017).

We previously documented that in $S$. microadriaticum, SmicHSP75 was significantly phosphorylated in Thr under darkness, but the phosphorylation levels decreased after a $30 \mathrm{~min}$ light stimulus (Castillo-Medina et al., 2019). Since the protein is a member of the HSP70 family and its dephosphorylation is stimulated by light, we had particular interest in exploring the effect of low and high temperature stress on the modulation of the Thr phosphorylation of this protein. In this work, we obtained a specific antibody and determined that the changes in Thr phosphorylation were not due to changes in the SmicHSP75 protein expression. We also evaluated the effect of low and elevated temperature stress on the levels of Thr phosphorylation in order to explore if a correlation with activation/inactivation of the chaperone with stress/normal growth temperature existed. We found that the light induced Thr dephosphorylation of SmicHSP75 was not due to a decreased protein expression and that high, but not low temperature, prevented the phosphorylation even under dark conditions suggesting an activation of the chaperone activity and inactivation during normal non-stressed growth throughout the dark phase of the photoperiod.

\section{MATERIAL AND METHODS}

\section{Antibodies and reagents}

Polyclonal anti-phosphothreonine (anti-pThr) antibodies were purchased either from Cell Signaling Technology, Inc. (Danvers, MA, USA) (cat. 9381S) or from Abcam (Cambridge, UK) (cat. AB9337). Polyclonal anti- bodies to a specific fragment of SmicHSP75 (anti-SBiP1; see below) were raised in a female white New Zealand rabbit (see below) and a fraction purified on a Protein G-sepharose column (Sigma; St. Louis, MO, USA) was used for the experiments. Alkaline-phosphatase (AP) conjugated polyclonal anti-rabbit $\operatorname{IgG}$ antibody raised in goat was from Zymed-Life Technologies (Grand Island, NY, USA). Reagents 5-bromo-4-chloro-3-indolyl phosphate (BCIP) and nitro blue tetrazolium (NBT) were from Promega (Madison, WI, USA).

\section{Symbiodinium microadriaticum cell cultures}

Dinoflagellate cultures of Symbiodinium microadriaticum Subsp. microadriaticum (clade A, also known as MACCassKB8) originally isolated from the jellyfish Cassiopea xamachana, and Breviolum psygmophilum (clade B, formerly referred to as Symbiodinium sp. Mf11.05b.01; CastilloMedina et al., 2019) were a kind gift of Dr. Mary Alice Coffroth (State University of New York at Buffalo). Fugacium kawagutii (clade F, previously referred to as Symbiodinium kawagutii; Castillo-Medina et al., 2019) were a kind gift of Dr. Robert K. Trench (University of California at Santa Barbara). Cultures were routinely maintained in our laboratory in ASP-8A medium under photoperiod cycles of $12 \mathrm{~h}$ light/dark at $26^{\circ} \mathrm{C}$. Light intensity for routine culture was maintained at $80-120 \mu \mathrm{mol}$ photons $\mathrm{m}^{-2} \mathrm{sec}^{-1}$.

\section{Multiple sequence alignment of BiP sequences}

B. minutum, S. kawagutii and S. pilosum ortholog sequences were identified in the Reefgenomics database (https://reefgenomics.org/), the corresponding sequences from Toxoplasma gondii chaperonin protein BiP ('Tgon, ME49 XP_002364404.1), Cryptosporidium muris heat shock protein $70^{-}$(Cmur, RN66 XP_002142079.1), Plasmodium malariae heat shock protein 70 (Pmal, SBT70952.1) and Arabidopsis thaliana (Atha, CAD5333706.1) were also included. The multiple sequence alignment was generated by the MULTALIN multiple alignment tool (Corpet, 1988).

\section{SDS-PAGE gel electrophoresis and western blot}

The protein extracts were prepared with dark-adapted 6-d-old S. microadriaticum cells $\left(5-9 \times 10^{5}\right.$ cells $\left./ \mathrm{ml}\right)$ which were concentrated by centrifugation at $2600 \times g, 25^{\circ} \mathrm{C}$ for $5 \mathrm{~min}$, the supernatant discarded, and the cell pellet suspended in $300 \mu \mathrm{l}$ Laemmli sample buffer (Laemmli, 1970). This suspension was immediately added to a tube containing a matrix volume of $250 \mu$ glass beads (425-600 $\mu \mathrm{m})$ and subjected to strong agitation at 48000 oscillations/minute for $3 \mathrm{~min}$ at $4^{\circ} \mathrm{C}$ in a MINI-BEAD BEATER-1 ${ }^{\circledR}$ (BioSpec Products; Bartlesville, OK, USA). The lysate was then heated at $95^{\circ} \mathrm{C}$ for $5 \mathrm{~min}$, centrifuged at $13000 \times \mathrm{g}$ for $10 \mathrm{~min}$, and the supernatant containing the proteins was analyzed by sodium dodecyl sulfate-polyacrylamide gel electrophoresis (SDS-PAGE) in discontinuous denaturing gels (Laemmli, 1970) of 10\% polyacrylamide in the separation zone $[375 \mathrm{mM}$ Tris$\mathrm{HCl}, \mathrm{pH} 8.8 ; 10 \%$ acrylamide/bis-acrylamide; $0.1 \%$ SDS; $0.1 \%$ ammonium persulphate (APS); $0.106 \% \mathrm{~N}, \mathrm{~N}, \mathrm{~N}$, $\mathrm{N}$-tetramethylethylenediamine (TEMED)], and 4\% polyacrylamide in the stacking zone $[125 \mathrm{mM}$ Tris- $\mathrm{HCl}, \mathrm{pH}$ 6.8; 4\% acrylamide; $0.137 \%$ bisacrylamide; $0.1 \%$ SDS; $0.1 \%$ APS; $0.066 \%$ TEMED] in a Mini-PROTEAN ${ }^{\circledR 3}$ System (BIO-RAD, Hercules, CA, USA). After electrophoresis, the proteins were transferred to PVDF membranes in "friendly buffer" (25 mM Tris-HCl, $192 \mathrm{mM}$ 
glycine, 10\% isopropanol; Villanueva, 2008) at a constant current of $300 \mathrm{~mA}$ for $1 \mathrm{~h}$. The membranes were blocked with gentle agitation in a solution of: $3 \%$ bovine serum albumin (BSA) in PBS $\left(2.79 \mathrm{mM} \mathrm{NaH} \mathrm{PO}_{4}\right.$, $7.197 \mathrm{mM} \mathrm{Na}_{2} \mathrm{HPO}_{4}, 136.9 \mathrm{mM} \mathrm{NaCl}, \mathrm{pH}$ 7.5) for $1 \mathrm{~h}$ at $50^{\circ} \mathrm{C}$ when anti-pThr antibodies from Cell Signaling Technology were to be used; or 5\% BSA in TBS $(20$ $\mathrm{mM}$ Tris-Base, $150 \mathrm{mM} \mathrm{NaCl}, \mathrm{pH} 7.5$ ) for $1 \mathrm{~h}$ at $4^{\circ} \mathrm{C}$ for the equivalent antibodies from Abcam. After blocking, the primary antibodies anti-pThr (1:2500; Cell Signaling Technology) or anti-SBiP1 (1:2500) were diluted in $0.01 \%$ Triton X-100 in PBS (PBS-T), added to the membranes, and incubated overnight with gentle rocking at room temperature. For all subsequent manipulations with anti-pThr from Abcam (1:500), dilutions were in $0.01 \%$ Triton $\mathrm{X}-100$ in TBS (TBS-T), and incubations and washes at $4{ }^{\circ} \mathrm{C}$. Then, the membranes were washed five times, $5 \mathrm{~min}$ each, in PBS-T or TBS-T, and incubated with alkaline-phosphatase conjugated anti-rabbit $\operatorname{IgG}$ at $1: 2500$ dilution for $2 \mathrm{~h}$ at room temperature or $4^{\circ} \mathrm{C}$. Subsequently, the membranes were washed again five times, 5 min with PBS-T or TBS-T. Finally, they were developed with a commercial solution of BCIP and NBT according to manufacturer's instructions except that for anti-pThr from Cell Signaling Technology the development buffer used was PBS-T.

\section{Enrichment and separation by two-dimensional gel electrophoresis of SmicHSP75 isoforms and subsequent analysis with anti-SBiP1 and anti-pThr antibodies}

Protein extracts from dark-adapted $S$. microadriaticum cells were prepared as above and analyzed by two-dimensional (2D) gel electrophoresis. The extracts were run on two preparative 10\% SDS-PAGE gels $(7 \mathrm{~cm} \times 6 \mathrm{~cm})$, and then cut widthwise between the 70 and $90 \mathrm{kDa}$ markers. Subsequently, both strips of the gels were macerated in liquid nitrogen, and the powder suspended in $3 \mathrm{ml}$ PBS followed by dialysis in an $8 \mathrm{kDa}$ MWCO Spectra/Por ${ }^{\circledR}$ (Spectrum Chemical Mfg. Corp.; New Brunswick, NJ, USA) dialysis bag against PBS overnight at $4^{\circ} \mathrm{C}$. The dialyzed proteins were then precipitated with the Cleanup ReadyPrep ${ }^{\circledR} 2 \mathrm{D}$ kit (BioRad), according to the manufacturer's methodology. The proteins were suspended and separated by isoelectric focusing as previously described (Castillo-Medina et al., 2019). After isoelectrofocusing, the strips were briefly rinsed in running buffer and ran in the second dimension on a $10 \%$ polyacrylamide SDSPAGE gel $(16 \mathrm{~cm} \times 16 \mathrm{~cm})$. After the run, the gel was stained with coomassie blue and the spots corresponding to SmicHSP75 were analyzed separately with both anti-pThr and anti-SBiP1 antibodies by western blot. As negative control, a random spot from the $2 \mathrm{D}$ gel was also excised and analyzed in parallel with the same antibodies.

\section{Cloning and heterologous expression of a specific peptide from SmicHSP75}

A 95 amino acid sequence from the identified $\mathrm{SmicH}$ SP75 isoform near the C-terminus (Fig. 1B, bolded amino acids) was selected based on both, low identity (49\% identity to the most similar S. microadriaticum BiPlike isoform), and antigenicity according to the EMBOSS explorer program (https://www.bioinformatics.nl/emboss-explorer/). The corresponding nucleotide sequence named c-term-SmicHSP75 was amplified by PCR as previously described (Islas-Flores et al., 2019), using the oligonucleotides Forward (Fw1) 5'-gaggagttcgcggatgaggacaagaagg-3' and Reverse (Rv1) 5'-gccgccgtagtacttggagacgatgg
-3' that flank the 285 bp stretch encompassing the c-termSmicHSP75 fragment. The PCR product was purified from a band separated on a 1\% agarose gel using the Wizard $^{\circledR}$ SV Gel and PCR Clean-Up System (Promega) according to the manufacturer's instructions. The purified fragment was inserted in a $\mathrm{pGEM}^{\mathbb{B}}-\mathrm{T}$ easy vector with T4 ligase (Promega) after which, it was transformed into chemically competent $\mathrm{DH} 5 \alpha$ E. coli cells according to the manufacturer's instructions. Transformed bacteria were grown in $950 \mu \mathrm{l} \mathrm{SOB} \mathrm{(2 \%} \mathrm{bacto-triptone,} 0.5 \%$ yeast extract, $0.01 \mathrm{M} \mathrm{NaCl}, 0.0024 \mathrm{M} \mathrm{KCl}, \mathrm{pH}$ 7) media for $2 \mathrm{~h}$ at $37^{\circ} \mathrm{C}, 200 \mathrm{RPM}$ (Lab companion SI300R incubator; Billerica, MA, USA), followed by inoculation on solid LB ( $1 \%$ bacto-triptone, $0.5 \%$ yeast extract, $0.171 \mathrm{M} \mathrm{NaCl}, 1.5 \%$ agar, $\mathrm{pH}$ 7.4) media added with $100 \mu \mathrm{g} / \mathrm{ml}$ ampicillin for selection. Transformed colonies were further selected by PCR amplification with T7 and Rv1 primers. This amplicon consisted of a 363 bp fragment that contained the 285 bp c-term-SmicHSP75 sequence and flanking fragments of the plasmid. Positive colonies were picked and propagated overnight in liquid LB media with $100 \mu \mathrm{g} / \mathrm{ml}$ ampicillin at $37^{\circ} \mathrm{C}$, 200 RPM. Plasmids were purified from grown bacteria using a Gene JET Plasmids Miniprep kit (Thermo Fisher Scientific; Waltham, MA, USA) according to the manufacturer's instructions. The selected plasmids were sequenced at the sequencing facility of the Institute of Biotechnology-UNAM (Cuernavaca, Morelos, México) to confirm the correct sequence identity. The c-termSmicHSP75 fragment was extracted from the pGEM ${ }^{\circledR}-\mathrm{T}$ easy vector with EcoRI (Thermo Fisher Scientific), and the corresponding band excised from a 1\% agarose gel was extracted with the QIAquick Gel extraction kit (QIAGEN; Hilden, Germany) according to the manufacturer's instructions. This fragment was inserted in the $\mathrm{pCR}^{\circledR} \mathrm{T} 7 / \mathrm{NT}-\mathrm{TOPO}^{\circledR}$ expression plasmid previously linearized with EcoRI at the insertion site, followed by T4 enzyme ligation (Promega). This plasmid harboring the insert (c-term-SmicHSP75-pCRT7/NT-TOPO) was transformed into chemically competent $\mathrm{DH} 5 \alpha \mathrm{E}$. coli cells fol-

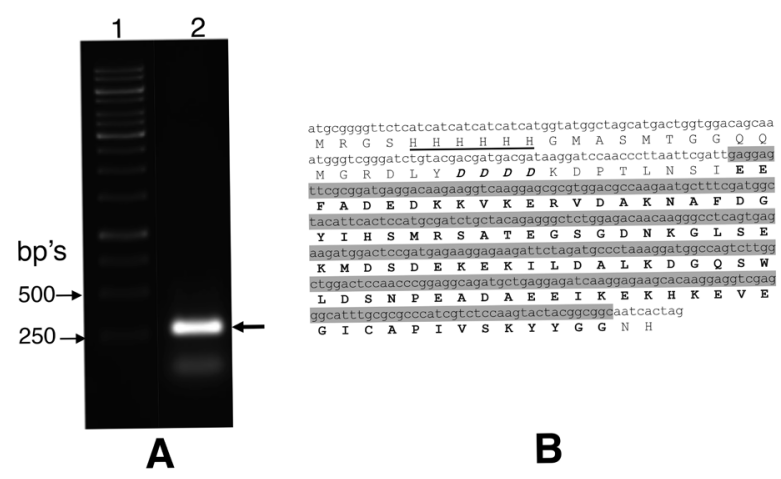

Figure 1. Amplification of the c-term-SmicHSP75 region from the SBIP1 sequence that encompasses the nucleotides that encode the peptide of interest, and confirmation that the amplicon harbors the expected sequence.

A) PCR amplification and observation of the $285 \mathrm{bp}$ amplicon (lane 2) corresponding to c-term-SmicHSP75 in an agarose gel exposed to UV light. Molecular size markers (lane 1) and their size in base pairs (bp's), are indicated by the arrows on the left. B) Nucleotide and corresponding translated amino acid sequences of the c-term-SmicHSP75-pCRT7/NT-TOPO plasmid fragment that contained the $375 \mathrm{bp}$ (lower case) encoding the hybrid fusion protein (named as c-term-SmicHSP75a) and containing c-term-SmicHSP75 (shaded in grey). The c-term-SmicHSP75 peptide sequence is shown (bolded amino acids). The six histidines that confer affinity to nickel are underlined. Bold italicized letters show an acidic region of four aspartic acids where enterokinase cleaves. 
lowed by selection as described above. Finally, plasmids were purified and sent for sequencing as above to confirm the correct sequence and in-frame assembly of the insert (Fig. 1B). For the plasmid expression, the c-termSmicHSP75-pCRT7/NT-TOPO vector was transformed into chemically competent BL21 D3 E. coli cells, as described above, except that the liquid LB media contained $100 \mu \mathrm{g} / \mathrm{ml}$ ampicillin. Cells from the same strain were transformed with the empty pCRT7/NT-TOPO vector in parallel as negative controls. Expression tests were carried out according to the manufacturer's methodology $\left(\mathrm{pCR}^{\circledR} \mathrm{T} 7 / \mathrm{NT}-\mathrm{TOPO}^{\circledR}\right.$ TA Expression Kits, Version J). We named the expressed hybrid c-term-SmicHSP75 protein fusion as c-term-SmicHSP75a (Fig. 1B). The protein from the transformed bacteria was visualized after 1, 2 and $4 \mathrm{~h}$ of growth by SDS-PAGE and coomassie blue staining.

\section{c-term-SmicHSP75a purification and enterokinase digestion}

Two hundred $\mathrm{ml}$ of a bacteria culture grown for 7 $\mathrm{h}$ in LB media (with $100 \mu \mathrm{g} / \mathrm{ml}$ ampicillin) was centrifuged for $8 \mathrm{~min}$ at $2600 \times g, 25^{\circ} \mathrm{C}$. The bacterial pellet was resuspended in $20 \mathrm{ml}$ binding buffer $(0.1 \mathrm{M}$ sodium phosphate, $0.4 \mathrm{M} \mathrm{NaCl}, 0.1 \mathrm{M} \mathrm{KCl}, 30 \mathrm{mM}$ imidazole, $6 \mathrm{M}$ urea, $0.5 \% \mathrm{TX}-100, \mathrm{pH} 7.4$, filter-sterilized through a $0.22 \mu \mathrm{m}$ Millipore filter; Millipore; Burlington, MA, USA), and lysed with 3 passages through a French pressure cell press (SLM/Aminco Inc.; Urbana, IL, USA) at 20000 psi. The lysed bacterial homogenate was centrifuged for $20 \mathrm{~min}$ at $20000 \times \mathrm{g}, 4^{\circ} \mathrm{C}$ and the supernatant was filtered-sterilized through a $0.22 \mu \mathrm{m}$ filter. All subsequent procedures were performed at $4^{\circ} \mathrm{C}$. The sample was applied onto a column packed with $1.5 \mathrm{ml}$ agarosenickel matrix (HIS-Select ${ }^{\circledR}$ Nickel Affinity Gel; Sigma), previously equilibrated with binding buffer and flow set at $10-15 \mathrm{ml} / \mathrm{h}$ with a peristaltic pump (P-1, Pharmacia Biotech; Erie, PA, USA). After binding, the column was washed with $100 \mathrm{ml}$ binding buffer; finally, the bound proteins were eluted with $10 \mathrm{ml}$ elution buffer (binding buffer adjusted to $200 \mathrm{mM}$ imidazole). Aliquots from the loaded solution, flowthrough, wash, and elution were analyzed on $16 \%$ polyacrylamide gels by SDS-PAGE and coomassie blue staining. The fractions containing the purified c-term-SmicHSP75a peptide were dialyzed against PBS overnight at $4^{\circ} \mathrm{C}$ in an $8 \mathrm{kDa}$ MWCO Spectra/Por ${ }^{\circledR}$ membrane (Spectrum Chemical Mfg. Corp.), and then stored at $-20^{\circ} \mathrm{C}$ for future removal of the hexahistidine stretch by bovine enterokinase. An enriched enterokinase fraction was obtained according to Liepnieks and Light (Liepnieks \& Light, 1979). Approximately $2 \mathrm{~m}$ of bovine duodenum was obtained from the local slaughterhouse (Cancún, Quintana Roo, México) and closed at the ends with strings for transportation to the laboratory. A solution of ice-cold $100 \mathrm{ml}$ buffer A $(20 \mathrm{mM}$ sodium acetate, $20 \mathrm{mM}$ acetic acid, $100 \mathrm{mM} \mathrm{CaCl}, 0.2 \%$ (v/v) TX-100, pH 4) was added to the duodenum to solubilize and drain its contents into a beaker; then, the organ was cut longitudinally and extended open so as to expose the internal wall. The mucous wall was gently scraped with the aid of drops of buffer A into the same beaker. All subsequent procedures were carried out at $4^{\circ} \mathrm{C}$. The collected material was adjusted to $200 \mathrm{ml}$ and stirred for $2 \mathrm{~h}$; then, the homogenate was sequentially filtered through a two-layer gauze and a $300 \mu \mathrm{m}$ nylon sieve that helped discard the particulate and floating fatty material. The filtrate was centrifuged at $20000 \times g$ for $30 \mathrm{~min}$ and the supernatant collected and adjusted to $\mathrm{pH} 8$ with 1
$\mathrm{M} \mathrm{NaOH}$; then, precipitation with ammonium sulfate was performed as follows: $40 \%\left(\mathrm{NH}_{4}\right)_{2} \mathrm{SO}_{4}$ with stirring for $6 \mathrm{~h}$, centrifugation at $14000 \times g$ for $1 \mathrm{~h}$ and the pellet discarded; more $\left(\mathrm{NH}_{4}\right)_{2} \mathrm{SO}_{4}$ was added to the supernatant to reach $80 \%$ followed by centrifugation as before, but in this case the pellet was recovered and resuspended in $1 \mathrm{ml}$ PBS followed by dialysis in a $8 \mathrm{kDa}$ MWC membrane (Spectra/Por ${ }^{\circledR}$; Spectrum Chemical Mfg. Corp.) against PBS overnight. After dialysis, the solution was loaded onto a $1.5 \times 50 \mathrm{~cm}$ glass Econo-Column ${ }^{\circledR}$ (BIORAD) packed with a $79 \mathrm{ml}$ Sephacryl S-300-HR matrix previously equilibrated with 2 vol PBSf (PBS, pH 7.8, filtered-sterilized through a $0.22 \mu \mathrm{m}$ membrane) at a rate of $30 \mathrm{ml} / \mathrm{h}(\sim 15 \mathrm{~cm}$ of column distance/h) and $790 \mu \mathrm{l}$ fractions collected. The column was previously calibrated with the molecular weight marker kit (MW-GF-1000 kit: dextran blue, apoferritin, $\beta$-amilase, BSA and citochrome C; Sigma), with Mr's 2000, 443, 200, 66, and $13 \mathrm{kDa}$, respectively, to determine the $\log _{10} \mathrm{MW}$-retention volume relationship. Thus, the fraction numbers 54-58 that included the $145 \mathrm{kDa}$ enterokinase were pooled and an aliquot was analyzed on a $7 \%$ polyacrylamide gel by SDS-PAGE under non-reducing conditions. The fraction was quantitated by the coomassie blue assay (Bradford, 1976), adjusted to $0.1 \mathrm{mg} / \mathrm{ml}$, and used as the active enterokinase fraction (AEF). Ten $\mu \mathrm{l}$ of $1 \mathrm{M}$ Tris- $\mathrm{HCl}, \mathrm{pH}$ 6.8 were combined with $5 \mu \mathrm{l}$ of the $0.1 \mathrm{mg} / \mathrm{ml} \mathrm{AEF}$ and this solution added with $85 \mu \mathrm{l}$ of the expressed c-termSmicHSP75a peptide at $0.459 \mathrm{mg} / \mathrm{ml}$, followed by incubation at $26^{\circ} \mathrm{C}$ for $6-36 \mathrm{~h}$ under darkness. The digested fractions were analyzed on $16 \%$ polyacrylamide SDSPAGE gels stained with coomassie blue. It was found that a $48 \mathrm{~h}$ digestion was optimal for removal of the extra histidines from the c-term-SmicHSP75a peptide that could interfere with the expected antigenic response; this digested peptide was termed c-term-SmicHSP75b.

\section{Preparation of polyclonal antibodies against the c-term- SmicHSP75b peptide}

The whole digestion mixture $(300 \mu \mathrm{l})$ containing the c-term-SmicHSP75b peptide was mixed with one third volume of $4 \times$ Laemmli buffer (Laemmli, 1970), heated at $95^{\circ} \mathrm{C}$ and run on two preparative $16 \%$ polyacrylamide gels by SDS- PAGE. With the aid of the coomassie blue-stained reference lanes, the zones corresponding to c-term-SmicHSP75b were excised from the gels, homogenized in liquid nitrogen and resuspended in $2 \mathrm{ml}$ PBS. This solution was dialyzed (3.5 kDa MWCO Spectra/Por ${ }^{\circledR}$ membrane) overnight against PBS at $4^{\circ} \mathrm{C}$. The dialysate was clarified by centrifugation at $2600 \times g, 4^{\circ} \mathrm{C}$ and run on a $16 \%$ polyacrylamide gel by SDS-PAGE to confirm that it contained the pure c-term-SmicHSP75b peptide. One hundred and fifty $\mu \mathrm{g}$ of c-term-SmicHSP75b in $500 \mu \mathrm{L}$ PBS were combined 1:1 with complete Freund's adjuvant and emulsified. The suspension was injected subcutaneously to a female white New Zealand rabbit in three different areas. Two more booster immunizations in incomplete Freund's adjuvant were applied after 5 and $31 \mathrm{~d}$, respectively. Bleeds from the rabbit ear were collected: prior to immunization (preimmune serum), and 5, 31 and $38 \mathrm{~d}$ post-immunization. The sera from the bleeds were collected and stored at $-70^{\circ} \mathrm{C}$ and some portions further purified on a Protein G-Sepharose column (Sigma), previously equilibrated with PB (PBS without $\mathrm{NaCl}$ ). After loading, the column was washed with 10 vol PB and eluted with $10 \mathrm{mM}$ glycine- $\mathrm{HCl}$, $\mathrm{pH}$ 3. The eluate was immediately neutralized with one tenth volume of $1 \mathrm{M}$ Tris- $\mathrm{HCl}, \mathrm{pH} 6.8$ and adjusted to 
$0.05 \%$ final vol with $\mathrm{NaN}_{3}$. The purified antibodies were named anti-SBiP1 (see below) and were stored at $4^{\circ} \mathrm{C}$ for future use.

\section{Light stimulation and preparation of protein extracts from Symbiodiniaceae}

All light stimulation treatments and subsequent analyses were carried out as three independent experiments and following the previously reported procedures (Castillo-Medina et al., 2019). Six-d-old cultures from S. microadriaticum, F. kawagutii or B. psygmophilum collected $2 \mathrm{~h}$ before the dark phase of the photoperiod, were concentrated and suspended in $40 \mathrm{ml}$ of fresh ASP-8A medium to reach $5-9 \times 10^{5}$ cells $/ \mathrm{ml}\left(2-3.6 \times 10^{7}\right.$ cells total $)$. The cells were placed in four $10 \mathrm{ml}$ aliquots $\left(\sim 5-9 \times 10^{6}\right.$ cells total $)$ in Falcon tubes wrapped with aluminum foil. The cells in the tubes were allowed to adapt in the dark (12 h) during their night cycle. After this period, each tube was exposed to a light intensity of $100 \mu \mathrm{mol}$ photon $\mathrm{m}^{-2} \mathrm{~s}^{-1}$ for 30,60 , and $240 \mathrm{~min}$ in the case of only light exposure at $26^{\circ} \mathrm{C}$. For light stimulation along with previous low or elevated temperature treatments, the tubes with cells were exposed to $650 \mu \mathrm{mol}$ photon $\mathrm{m}^{-2} \mathrm{~s}^{-1}$.

Then, the cells from each tube were sedimented by centrifugation as previously described (Castillo-Medina et al., 2019), suspended in Laemmli buffer (Laemmli, 1970), supplemented with $0.2 \mathrm{mM} \mathrm{NaVO}, 10 \mathrm{mM} \mathrm{NaPPi}$ and a cocktail of protease inhibitors (Complete ${ }^{\circledR}$; Roche, Basel, Switzerland), mixed with glass beads (425-600 $\mu \mathrm{m}$ diameter) and lysed with a MINI-BEAD BEATER-1 ${ }^{\circledR}$ (Biospec Products). The lysate was heated at $95^{\circ} \mathrm{C}$ for $5 \mathrm{~min}$ and the supernatant was used for western blot analysis. Equal loads of proteins were adjusted with equal aliquots of cells and also standardized by staining with coomassie blue on $10 \%$ polyacrylamide SDS-PAGE gels. Finally, the extracts were analyzed by western blot which included anti-SBiP1 antibodies as an internal loading control and to determine possible changes in protein expression. The bands from the triplicate samples were captured with a ChemiDoc-It ${ }^{\circledR} 2$ Imager (UVP-Analytik Jena, Upland, CA, USA) and analyzed by densitometry with the system's VisionWorks LS software, normalized with the internal SmicHSP75 control to obtain an arbitrary level of intensity for each antibody reaction. The results were integrated into graphs displaying the average band intensity of the three biological replicates for each treatment.

\section{Treatments of S. microadriaticum cells adapted to darkness with low and elevated temperature}

For treatments of $S$. microadriaticum cells adapted to darkness with moderately low and elevated temperature, a similar approach to the light stimulation experiment was used. Samples from 6-d-old cultures were centrifuged and resuspended in fresh ASP-8A medium to reach $5-9 \times 10^{5}$ cells $/ \mathrm{ml}$. Then, the suspension was divided in three sets of two $15 \mathrm{ml}$ Falcon tubes, each containing $10 \mathrm{ml}$ aliquots $\left(\sim 5-9 \times 10^{6}\right.$ cells total/sample) for each treatment, covered with foil and incubated $12 \mathrm{~h}$ in the dark at either 21,26 or $32^{\circ} \mathrm{C}$. After the incubation period, cells from one tube after each temperature treatment were placed in $3.5 \mathrm{~cm}$ diameter polystyrene wells and stimulated with $650 \mu \mathrm{mol}$ photon $\mathrm{m}^{-2} \mathrm{~s}^{-1}$ for $30 \mathrm{~min}$. The cells from the remaining tubes/treatments were kept in the dark during that time. The cells from all samples were then lysed as described above and the samples were analyzed by western blot with anti-pThr or antiSBiP1 antibodies. An equal load of protein per well in the gels was assured at all times as described above. As previously, three independent experiments were carried out for the treatments and analyses. To evaluate shortterm heat stress, two additional samples of dark-adapted cells were incubated, one at $26^{\circ} \mathrm{C}$ (control) and the other under darkness at $32^{\circ} \mathrm{C}$ (heat stressed) for 30-240 min only. Then, they were processed immediately for analysis by western blot with anti-PThr or anti-SBiP1 antibodies.

\section{RESULTS}

\section{Cloning, expression and purification of the c-term- SmicHSP75a peptide, a specific peptide absent in all other related sequences}

We previously identified several distinct sequences with identity to the SmicHSP75 homolog from the S. microadriaticum genome database. From these, at least three sequences, including SmicHSP75, corresponded to BiPlike proteins (Accession No's. OLP91134, OLP86850 and OLP81269; Castillo-Medina et al., 2019). Further analysis by multiple alignment revealed a high identity to BiP-like proteins from the three Symbiodiniaceae species F. kawagutii, B. minutum, and S. pilosum (Supplementary Fig. 1 at https://ojs.ptbioch.edu.pl/index.php/abp/), and to BiP-like proteins from other apicomplexans such as Toxoplasma gondii, Cryptosporidium muris, and Plasmodium malariae (Supplementary Fig. 1 at https://ojs.ptbioch.edu. $\mathrm{pl} /$ index.php/abp/). Furthermore, a close alignment was also observed with a BiP-like protein from Arabidopsis thaliana (Supplementary Fig. 1 at https://ojs.ptbioch.edu. $\mathrm{pl} /$ index.php/abp/). These data further confirmed our previous report (Castillo-Medina et al., 2019) that SmicHSP75 is indeed a BiP-like protein from S. microadriaticum.

From all the sequences identified in the $S$. microadriaticum genome only one matched $100 \%$ with the peptide sequences obtained from 2-D gel spots (Castillo-Medina et al., 2019). We identified a 95 amino acid stretch near the Cterminus from such sequence (Fig. 1B, bolded amino acids) that was selected based on both, low identity to the other BiP-like isoforms from $S$. microadriaticum, and antigenicity according to the EMBOSS explorer program. This sequence named c-term-SmicHSP75, also yielded good antigenicity (see methods). The corresponding c-term-SmicHSP75 nucleo-

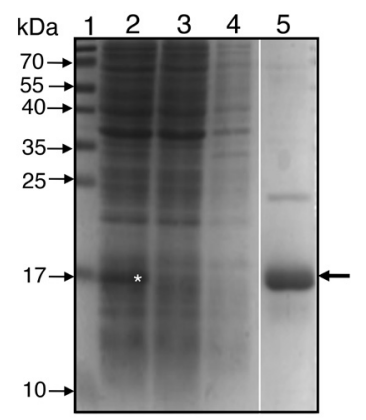

Figure 2. Expression and affinity purification of the c-termSmicHSP75a peptide.

The c-term-SmicHSP75a peptide was expressed in BL21 D3 Eschecrichia coli cells, the cells lysed, and the clarified lysate purified on a nickel affinity column. The figure shows the coomassie blue stained proteins, separated on a $16 \%$ polyacrylamide SDS-PAGE gel of the lysate before loading (lane 2), the flowthrough after (lane 3), first wash (lane 4) and eluate from (lane 5) the column. The c-term-SmicHSP75a peptide can be observed as a major protein of the total bacterial lysate (lane 2, asterisk), absent in the column flowthrough (lane 3) and wash (lane 4), and eluted as the main protein (lane 5, right arrow). Lane 1 shows the molecular weight markers with their values indicated in kDa next to the arrows on the left. 


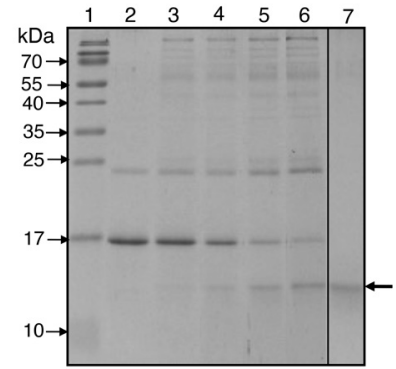

Figure 3. Digestion kinetics of the recombinant peptide c-termSmicHSP75a.

SDS-PAGE analysis of the purified c-term-SmicHSP75a peptide (lane 2), combined with the active enterokinase fraction obtained from bovine duodenum and incubated at $26^{\circ} \mathrm{C}$ under darkness for 6 (lane 3), 12 (lane 4), 24 (lane 5) and $36 \mathrm{~h}$ (lane 6). The digested fractions were analyzed on $16 \%$ polyacrylamide gels stained with coomassie blue. The major $\sim 17 \mathrm{kDa}$ peptide is clearly observed after 6 and $12 \mathrm{~h}$ of digestion but it gradually disappears after 24 and $36 \mathrm{~h}$, whereas the lower molecular weight $\sim 14 \mathrm{kDa}$ peptide (c-term-SmicHSP75b) gradually appears at the same incubation times (lanes 5 and 6, respectively; right arrow). Lane 7 (right arrow) shows the c-term-SmicHSP75b peptide isolated by excision of the corresponding band from a preparative gel. Lane 1 shows the molecular weight markers with their values indicated in $\mathrm{kDa}$ next to the arrows on the left.

tide sequence was successfully amplified by PCR (Fig. 1A, lane 2, arrow) and cloned into a plasmid that allowed its fusion with six histidines. The correct reading frame of the sequence (Fig. 1B, grey shaded) that included the six histidines (Fig. 1B, underlined amino acids) was corroborated by sequencing. When the insert was released and cloned for heterologous expression in BL21 D3 E. coli cells, one of the major proteins observed in the clarified bacterial extracts lysed after $2-4 \mathrm{~h}$ of culture was one of the expected $\mathrm{Mr} \sim 17$ $\mathrm{kDa}$ (Fig. 2, lane 2, asterisk) corresponding to the hybrid cterm-SmicHSP75a peptide. We observed the protein maximally expressed at $4 \mathrm{~h}$ of culture; in contrast, no equivalent major $17 \mathrm{kDa}$ protein was observed when a culture of the same bacteria transformed with the empty vector was analyzed (data not shown). Therefore, we grew a $200 \mathrm{ml}$ liquid culture for $7 \mathrm{~h}$ and the clarified bacterial lysate was used to purify the peptide on a nickel-affinity column. The abundant $17 \mathrm{kDa}$ band was present in the bacterial lysate prior to passage through the column (Fig. 2, lane 2, asterisk), but it was absent in the column flowthrough and wash (Fig. 2, lanes 3 and 4, respectively). Consequently, a strong $17 \mathrm{kDa}$ band was observed when the eluate from specific columnbound proteins was analyzed (Fig. 2, lane 5). This indicated that the c-term-SmicHSP75a peptide, specific for the SmicHSP75 protein, could be successfully expressed in the bacteria and obtained in a pure form for further processing.

\section{Digestion of c-term-SmicHSP75a with enterokinase and raising of specific antibodies}

The purified c-term-SmicHSP75a recombinant peptide contains an extra amino acid stretch with the six histidines (Fig. 1B, underlined amino acids) required for purification by nickel-affinity chromatography, but also four additional aspartates (Fig. 1B, bolded, italicized amino acids) that could elicit an important but undesirable immune response. Thus, the peptide was digested with the AEF, which targets the four aspartates and removes the extra histidines from the recombinant peptide. SDSPAGE analysis showed the strong band corresponding to the $17 \mathrm{kDa}$ peptide (Fig. 3, lane 2) in the initial extract, that gradually diminished after $6,12,24$ and $36 \mathrm{~h}$ of enterokinase digestion (Fig. 3, lanes 3-6, respectively).

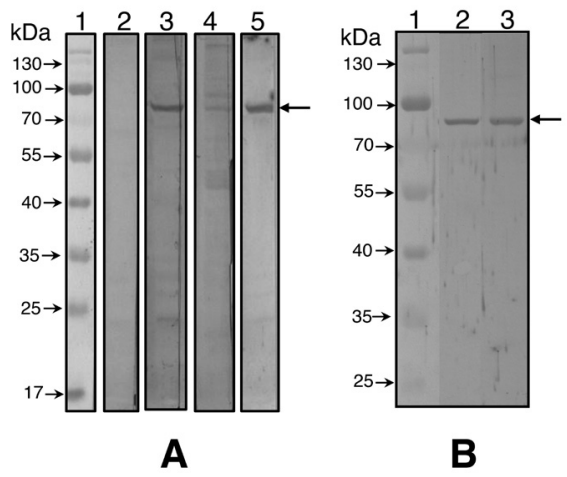

Figure 4. Analysis of the specificity of the anti-SBiP1 antibody in Symbiodinium microadriaticum and cross-reactivity with other Symbiodiniaceae species.

A) The serum containing the anti-SBiP1 antibody was affinitypurified on a protein G-sepharose column and the specificity of both, the whole serum and purified IgG fraction analyzed. Total homogenates from logarithmic phase growing S. microadriaticum cells were obtained and analyzed by western blot with the preimmune rabbit serum (lane 2), the immune anti-SBiP1 serum (lane 3), anti-pThr antibodies (lane 4) and the IgG fraction purified from the anti-SBiP1 serum (lane 5). The $75 \mathrm{kDa}$ band (right arrow) was clearly observed in both lanes probed with the immune serum (lane 3 ) and IgG fraction (lane 5) containing the antiSBiP1 antibodies, whereas no equivalent band was observed in the lane probed with the preimmune serum (lane 2). In addition, the $75 \mathrm{kDa}$ band observed with anti-SBiP1 co-migrates with the $75 \mathrm{kDa}$ band detected with anti-pThr antibodies (lane 4). B) The anti-SBiP1 lgG fraction cross-reacted and specifically recognized a $75 \mathrm{kDa}$ band (right arrow) in western blot analysis of total homogenates from Breviolum psygmophilum (lane 2) and Fugacium kawagutii (lane 3). Lanes 1 from both panels show the molecular weight markers with their values indicated in $\mathrm{kDa}$ next to the arrows on the left.

On the other hand, the presence of a lower molecular weight peptide gradually appeared after 12, 24 and $36 \mathrm{~h}$ of digestion (Fig. 3, lanes 4-6, respectively, thick right arrow). The new digested peptide was named c-termHSP75b and was further purified using preparative gels which yielded a single $\mathrm{Mr} \sim 14 \mathrm{kDa}$ band (Fig. 3, lane 7 , thick right arrow), and was used to raise specific antiSmicHSP75 antibodies. Both the whole serum and IgG fraction of the anti-SBiP1 antibodies showed a specific reaction against a $75 \mathrm{kDa}$ protein from a total homogenate of $S$. microadriaticum proteins (Fig. 4A, lanes 3 and 5 , respectively), and which co-migrated with the 75 $\mathrm{kDa}$ protein immunodetected with anti-pThr antibodies (Fig. 4A, lane 4). In contrast, the preimmune serum did not show any reaction against the same homogenate (Fig. 4A, lane 2). As expected from our previous results, which showed that SmicHSP75 was present in two other species of Symbiodiniaceae (Castillo-Medina et al., 2019), anti-SBiP1 antibodies also cross-reacted with whole homogenates from B. psygmophilum and F. kawagutii (Fig. 4B, lanes 2 and 3, respectively). Interestingly, blast analysis also yielded similar sequences present in $S$. pilosum and $S$. natans (not shown). Derived from the fact that these data suggest that the protein is present in various (if not all) species from Symbiodiniaceae, and most likely represents one of several isoforms present in S. microadriaticum, we re-named it as SBiP1 ( Symbiodiniaceae Binding $\underline{\text { Protein }}$ 1). Consequently, the antibody was named anti-SBiP1.

\section{Anti-SBiP1 antibodies specifically detect the phosphorylated isoforms of SBiP1}

To demonstrate that the antibodies against SBiP1 immunoreact with the same Thr phosphorylated $75 \mathrm{kDa}$ protein, we separated the proteins by SDS-PAGE and the 

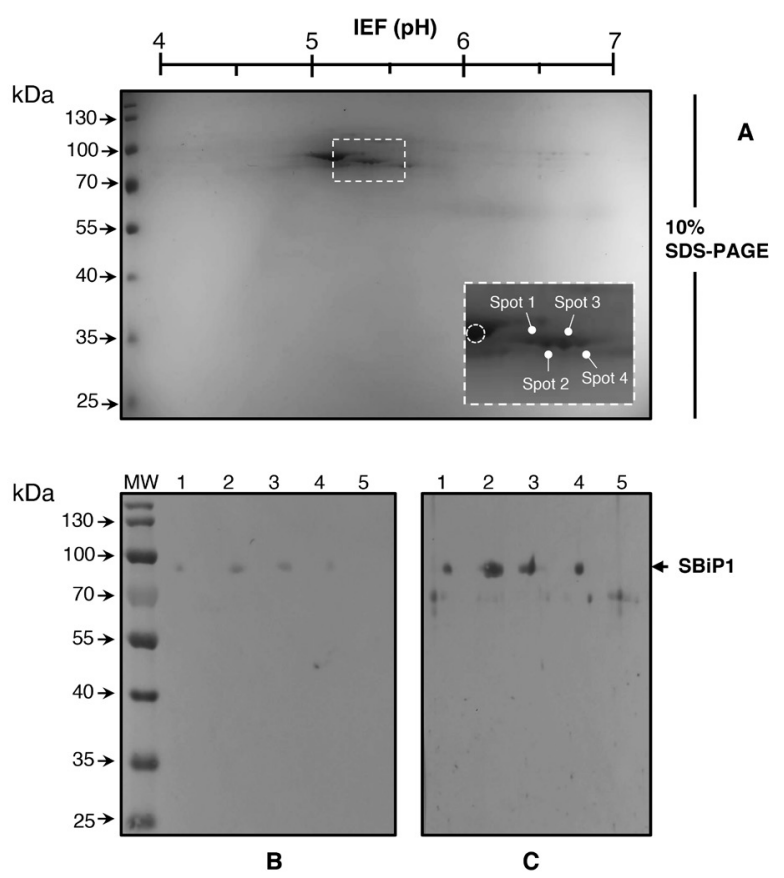

Figure 5. Anti-SBiP1 antibodies specifically detect the Thr phosphorylated isoforms of SBiP1.

Symbiodinium microadriaticum proteins were analyzed by 2D-gel electrophoresis and visualized by coomassie blue (A). The various spots migrating at the SBiP1 position were localized (white frame and inbox), and excised from the gel, then ran individually on a second dimension and analyzed by western blot with anti-pThr (B) or anti-SBiP1 (C) antibodies. Immunostaining was observed with both anti-pThr (B, lanes 1-4) and anti-SBiP1 ( $C$, lanes 1-4) antibodies, which correspond to spots $1-4$, respectively. A random spot (circle in inbox) was also excised and ran in parallel as a negative control showing no signal for both immunoblots $(B, C$; lanes 5). The arrows on the left of (A) and (B) indicate the molecular weight markers in $\mathrm{kDa}$; the top bar in (A) shows the $\mathrm{pH}$ values of the gradient after isoelectrofocusing.

$75 \mathrm{kDa}$ region was excised and processed for further separation by $2 \mathrm{D}$-electrophoresis (Fig. 5A). This procedure allowed us to detect four distinct isoforms recognized by the anti-p'Thr antibody (Fig. 5A, inbox, arrows). We then excised the equivalent spots from a parallel gel and analyzed them separately by western blot with either antipThr or anti-SBiP1 antibodies. We observed the specific

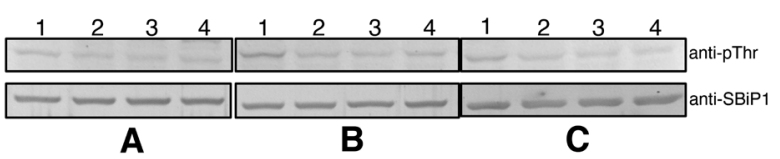

Figure 6. Changes in Thr phosphorylation of SBiP1 do not reflect changes in its expression.

SBiP1 levels of Thr phosphorylation from three different species of Symbiodiniaceae after $12 \mathrm{~h}$ of growth under dark conditions followed by exposure to light. Total extracts were prepared from the cells and western blot analysis was carried out to detect SBiP1 Thr phosphorylation (upper panel) or total SBiP1 levels (lower panel). Maximum levels of SBiP1 Thr phosphorylation (upper panel) are observed under dark conditions (lanes 1) in Symbiodinium microadriaticum (A), Breviolum psygmophilum (B), and Fugacium kawagutii (C). As previously reported (Castillo-Medina et al., 2019), a trend of Thr dephosphorylation of SBiP1 is observed after the cells were exposed for 30 (lanes 2), 60 (lanes 3), or 240 min (lanes 4) to $100 \mu \mathrm{mol}$ photon $\mathrm{m}^{-2} \mathrm{~s}^{-1}$ light. On the other hand, the presence of total SBiP1 (lower panel) is observed without changes under darkness (lanes 1 ) or after light exposure at all times analyzed (lanes 2-4). immunostaining of each spot by anti-pThr (Fig. 5B, lanes $1-4)$, confirming that they were differentially phosphorylated isoforms of the same $75 \mathrm{kDa}$ protein. Furthermore, when the same spots were analyzed by anti-SBiP1 antibodies, they recognized the $75 \mathrm{kDa}$ protein (Fig. 5C, lanes $1-4)$ indicating that they were specific against the $75 \mathrm{kDa}$ Thr-phosphorylated protein. A random spot excised from the 2-D gel, which was also analyzed in parallel, showed no reaction with either antibody (Figs. 5B, C, lanes 5).

\section{Detected changes in the level of phosphorylation of SBiP1 (SmicHSP75) do not arise from changes in protein expression}

Previous studies demonstrated that SBiP1 was highly phosphorylated on Thr during the dark phase of growth of S. microadriaticum and that, after $30 \mathrm{~min}$ of light stimulation, this phosphorylation level decreased $\sim 50 \%$ (Castillo-Medina et al., 2019). With the availability of specific antibodies to $\mathrm{SBiP} 1$, we repeated the experiments to compare the variations in phosphorylation levels with possible variations in total SBiP1 protein levels. We observed the expected decrease in Thr phosphorylation after 30,60 and $240 \mathrm{~min}$ of light stimulation on dark-adapted cells (Fig. 6A, upper panel, lanes $2,3,4$, respectively) analyzed with anti-p'Thr antibodies. In contrast, analysis with anti-SBiP1 antibodies showed that the total SBiP1 levels remained unchanged, either with (Fig. 6A, lower panel, lanes 2-4) or without (Fig. 6A, lower panel, lane 1) the light exposure treatments. Furthermore, these results were reproduced when identical analyses were carried out on B. psygmophilum and F. kawagutii (Figs. 6B and $\mathrm{C}$, respectively). This indicated that the detected changes in Thr phosphorylation levels of SBiP1 after light stimulation were not due to changes in expression of the protein.

\section{Stress at elevated but not at low temperature under dark conditions induces both SBiP1 Thr dephosphorylation and re-phosphorylation to basal levels after light exposure}

S. microadriaticum cells normally grow at $26^{\circ} \mathrm{C}$ and under light and dark photoperiod. Under dark-adapted conditions, SBiP1 displays a high level of Thr phosphorylation (Fig. $6 \mathrm{~A}-\mathrm{C}$, lanes 1; Fig. $7 \mathrm{~A}$ upper panel, lane $26^{\circ} \mathrm{C}$-dark and Fig. $7 \mathrm{~B}$, grey bars above $26^{\circ} \mathrm{C}$ ) that is markedly decreased after $30 \mathrm{~min}$ of light exposure at either 100 (Fig. 6A-C, lanes 2 , respectively) or $650 \mu \mathrm{mol}$ photon $\mathrm{m}^{-2} \mathrm{~s}^{-1}$ (Fig. 7A upper panel, $26^{\circ} \mathrm{C}$-light and Fig. $7 \mathrm{~B}$, white bars above $26^{\circ} \mathrm{C}$ ). In contrast, when $S$. microadriaticum cells were incubated at $32^{\circ} \mathrm{C}$ for $12 \mathrm{~h}$ in the dark, SBiP1 Thr phosphorylation levels were minimal (Fig. 7A upper panel, lane $32^{\circ} \mathrm{C}$-dark; Fig. 7B, dark bar above $32^{\circ} \mathrm{C}$. However, $30 \mathrm{~min}$ after the $32^{\circ} \mathrm{C}$ stressed cells were exposed to light, SBiP1 showed a re-phosphorylation (Fig. 7A upper panel, lane $32^{\circ} \mathrm{C}$-light; Fig. 7B, white bar above $32^{\circ} \mathrm{C}$ ) to levels comparable to those observed in the control of dark-adapted cells at $26^{\circ} \mathrm{C}$ after light stimulation (Fig. $7 \mathrm{~A}$ upper panel, lane $26^{\circ} \mathrm{C}$-light; Fig. 7B, white bar above $32^{\circ} \mathrm{C}$ ). Interestingly, cells growing under dark conditions at the lower temperature of $21^{\circ} \mathrm{C}$ showed a high SBiP1 Thr phosphorylation level similar to that from cells incubated at the control $26^{\circ} \mathrm{C}$ temperature (Fig. 7A upper panel, lane $21^{\circ} \mathrm{C}$-dark; Fig. $7 \mathrm{~B}$, black bar above $21^{\circ} \mathrm{C}$ ). Consequently, a dephosphorylation behavior after exposure to light, similar (but not identical) to that from cells incubated at the control $26^{\circ} \mathrm{C}$ temperature was observed (Fig. $7 \mathrm{~A}$ upper panel, lane $21^{\circ} \mathrm{C}$-light; Fig. $7 \mathrm{~B}$, white bar above $21^{\circ} \mathrm{C}$ ). The Thr dephosphorylation response of SBiP1 was also observed in short-term heat-shocked cells. The high levels of Thr phosphorylation observed at $26^{\circ} \mathrm{C}$ under dark conditions (Supplementary Fig. 2, lane 1 at https://ojs.ptbioch. 

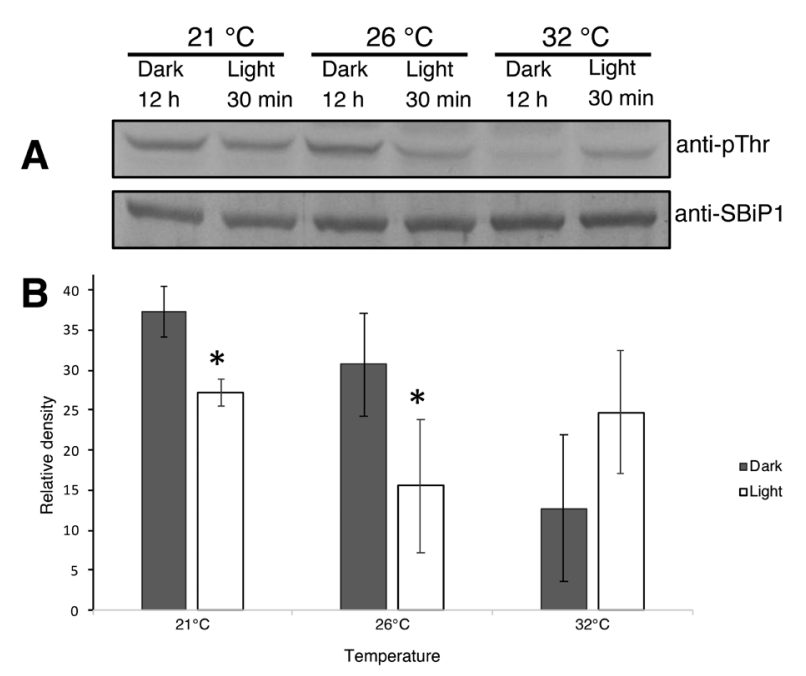

Figure 7. High levels of Thr phosphorylation of SBiP1 under darkness are disrupted by high but not low temperature longterm treatments.

Western blot analysis of total extracts prepared from dark-adapted (Dark) Symbiodinium microadriaticum cells incubated at 21, 26 or $32^{\circ} \mathrm{C}$, followed by exposure to light for $30 \mathrm{~min}$ at $650 \mu \mathrm{mol}$ photon $\mathrm{m}^{-2} \mathrm{~s}^{-1}$ (Light). The SBiP1 band detected with anti-pThr antibodies (upper panel) was observed highly phosphorylated under darkness at $21^{\prime}$ (Dark, $21^{\circ} \mathrm{C}$ ) and $26^{\circ} \mathrm{C}$ (Dark, 26年) but not when the darkness adaptation period was carried out at $32^{\circ} \mathrm{C}$ (Dark, $32^{\circ} \mathrm{C}$ ). Light exposure caused a decrease in SBiP1 Thr phosphorylation at 21 (Light, $21^{\circ} \mathrm{C}$ ) and $26^{\circ} \mathrm{C}$ (Light, $26^{\circ} \mathrm{C}$ ) whereas at $32^{\circ} \mathrm{C}$ (Light, $\left.32^{\circ} \mathrm{C}\right)$, re-phosphorylation to basal levels occurred. Total SBiP1 levels (lower panel) remained unchanged regardless of the treatment applied. Densitometric analysis normalized with the corresponding total SBiP1 bands confirmed that the differences in the levels of phosphorylation were statistically significant $\left(^{*}\right)$.

edu.pl/index.php/abp/) drastically diminished when the dark-adapted cells were incubated for $30 \mathrm{~min}$ at $32^{\circ} \mathrm{C}$ under dark conditions (Supplementary Fig. 2, lane 3 at https:// ojs.ptbioch.edu.pl/index.php/abp/), and even after 1 and 4 $\mathrm{h}$ at $32^{\circ} \mathrm{C}$ under darkness (Supplementary Fig. 2, lanes 4 and 5, respectively, at https://ojs.ptbioch.edu.pl/index.php/ $\mathrm{abp} /$ ). For comparison, dark-adapted cells at $26^{\circ} \mathrm{C}$ were exposed to light for $30 \mathrm{~min}$ without temperature change to show that the Thr dephosphorylation response occurred as expected (Supplementary Fig. 2, compare lanes 1 and 2 at https://ojs.ptbioch.edu.pl/index.php/abp/). These results indicated that the elevated temperature profoundly affected the SBiP1 Thr phosphorylation behavior in S. microadriaticum, whereas the lower temperature did not.

\section{DISCUSSION}

Even though protein modifications by phosphorylation are fundamental for cellular regulation and signaltransduction pathways, this field has been largely unexplored in Symbiodiniaceae. We have previously reported the presence of numerous proteins phosphorylated on Ser, Thr, and Tyr in three different species of Symbiodiniaceae (Castillo-Medina et al., 2019). We also demonstrated that one of these proteins of $M_{\mathrm{r}} \sim 75 \mathrm{kDa}$ was present and responded to a light stimulus through Thr dephosphorylation in all three species analyzed. The protein was identified as a BiP-like protein from the HSP70 protein family (Castillo-Medina et al., 2019). The sequence analysis revealed at least 6 related sequences in S. microadriaticum, and blast analysis against Symbiodiniaceae also revealed homologs in other species. Furthermore, although the BiP orthologs of B. minutum and
F. Kawagutii have not yet been characterized, the corresponding sequences were identified in the Reefgenomics database and a multiple alignment confirmed their identity as BiPs (Supplementary Fig. 1 at https://ojs.ptbioch. edu.pl/index.php/abp/); therefore, we named this particular isoform as SBiP1 (see above).

Multiple potential Thr phosphorylation sites in SBiP1 are likely to be the targets of the kinase(s) responsible for the differentially phosphorylated isoforms previously detected (Castillo-Medina et al., 2019) and also reported here (Fig. 5). In addition, several genes encoding at least 6 HSP70-related proteins were found in the annotated $S$. microadriaticum genome (Aranda et al., 2016). The genomic isoforms along with those arising from post-translational phosphorylations suggest a tightly controlled regulation of the pathways in which these proteins are involved. Phosphorylation is also the switch for regulation of the BiP chaperone function whereby phosphorylated/dephosphorylated BiP's are the inactive/active forms, respectively (Hendershot et al., 1988; Gaut, 1997; Díaz-Troya et al., 2011). Therefore, external factors capable of inducing changes in the SBiP1 phosphorylated status would also be the result of those factors causing changes in its chaperone activity. We have previously shown that under dark conditions, SBiP1 is highly phosphorylated in Thr, thus reflecting an inactive chaperone status; upon light exposure of the $S$. microadriaticum cells, SBiP1 is dephosphorylated in Thr, suggesting a light-activated mechanism that ultimately results in the activation of the chaperone function.

In order to rule out that the observed decrease in Thr phosphorylation was due to changes in the expression of the protein, we used a specific antibody against SBiP1. Since there were several BiP-related sequences in S. microadriaticum, we required a specific antibody. Thus, we raised polyclonal antibodies using a recombinant peptide derived from a sequence of 95 amino acids near the Cterminus of SBiP1 (Fig. 1B, bolded amino acids). This peptide was chosen based on low identity (49\% identity to the most similar $S$. microadriaticum BiP-like isoform) and high antigenicity (according to the EMBOSS explorer program). The resulting anti-SBiP1 antibodies were highly specific towards all detected SBiP1 isoforms from S. microadriaticum (Fig. 5), confirming their usefulness for assessing possible changes in protein expression. Furthermore, the antibodies also recognized a similar $\sim 75 \mathrm{kDa}$ protein from B. psygmophilum and F. kawagutii, indicating that they cross-reacted with the putative SBiP1 homologs in these other Symbiodiniaceae species. We then reproduced the experiment of light induced Thr dephosphorylation using the antibodies in parallel with anti-pThr antibodies. The results confirmed that the detected light-induced BiP dephosphorylation was indeed due to changes in the Thr phosphorylation levels and not to changes in protein expression as the SBiP1 protein levels remained unchanged throughout the timecourse of the experiment. Even though transcriptomic data of differential expression in $S$. microadriaticum upon long-term exposure to high temperature $\left(31^{\circ} \mathrm{C}\right)$ have revealed up-regulated expression of proteins of the HSP70 family (Gierz et al., 2017), there are several important differences that could account for our observations of constant SBiP1 expression. First, our long-term exposure to high temperature consisted of a maximum of $12 \mathrm{~h}$ in the dark followed by analyses through a maximum of $4 \mathrm{~h}$ after light exposure, whereas Gierz and collaborators (Gierz et al., 2017) observed up-regulated expression of HSP70-like proteins in S. microadriaticum after $4 \mathrm{~d}$ of the heat treatment; second, changes in gene expression may be subtle and not detected in protein analyses by 
western blot; and last, gene expression is not necessarily strictly correlated to protein expression (Liu et al., 2016). As mentioned above, both gene expression and posttranslational modifications are important for highly regulated processes; post-translational modifications may be the initial early responses followed by changes in gene expression at later stages. A transcriptomic study using a short-term heat shock approach should reveal whether changes in expression of these proteins in S. microadriaticum also occur as early responses to heat stress. Finally, the observation of a homogeneous pattern in all the lanes analyzed with anti-SBiP1 antibodies also allowed for their use in the control of uniform protein load on the gels and, at the same time, normalization of band intensity in the densitometric analyses.

A phosphoamino acid analysis of mammalian BiP demonstrated that this protein is predominantly phosphorylated on threonine and to a lesser extent on serine residues (Hendershot et al., 1988). Consistent with this, we previously detected at least two isoforms of SBiP1 (SmicHSP75; Castillo-Medina et al., 2019); however, a more detailed analysis revealed at least four SBiP1 isoforms (Fig. 5). This suggests that several SBiP1 sites are phosphorylated on threonine, although we cannot rule out a single Thr phosphorylation and isoforms arising from other types of post-translational modifications. In fact, other post-translational modifications such as ADP ribosylation and AMPylation of mammalian BiP's have been reported (Hendershot et al., 1988; Ham et al., 2014). On the other hand, there are no reports to date of modifications of ADP ribosylation or AMPylation of $\mathrm{BiP}$ in plants or photosynthetic microalgae. In fact, AMPylation is presumed to be a modification restricted to animal cells (Preissler \& Ron, 2019).

We observed a light induced Thr dephosphorylation response of SBiP1 in S. microadriaticum cells, which, based on the available evidence, we interpret as activation of its chaperone activity regulated by this post-translational modification. Indeed, regulated activation/inactivation by phosphorylation/dephosphorylation of BiP chaperones has led to their conceptualization as regulatory masters of the ER because they play crucial roles in the processes of synthesis, folding, assembly and translocation of proteins through the ER (Hendershot, 2004). Under basal conditions, light could be the stimulus that triggers these processes in the Symbiodiniaceae ER. Only a few studies describe a relationship between BiP chaperones and light, much less, changes in their phosphorylation state in response to light. One of these reported that, in Chlamydomonas reinhardtii, light induced the expression of a chloroplast HSP70 (Kropat et al., 1995). Protein synthesis is another pathway in which regulation of BiP by phosphorylation has been reported to play a role. For example, $\mathrm{CrBiP}$ (the C. reinhardtii homolog of $\mathrm{BiP}$ ) is activated by dephosphorylation at the onset of de novo protein synthesis, which occurs downstream of the TOR (Target of Rapamycin) pathway (Díaz-Troya et al., 2011). More studies are necessary to determine whether SBiP1 is also involved in similar protein synthesis regulatory pathways in Symbiodiniaceae.

It has been clearly demonstrated that stresses that increase the need for active $\mathrm{BiP}$, such as glucose starvation or tunicamycin treatment, promote its dephosphorylation and thus its association with client proteins (Hendershot et al., 1988; Satoh et al., 1993; Díaz-Troya et al., 2011). The light induced Thr dephosphorylation response, and thus activation of the BiP chaperone activity, may be part of a protective mechanism that allows the cells to contend with a number of new external conditions imposed by the irradiated light, and that are translated as stressful conditions to the cells. A number of these could be the light incidence itself and generation of ROS (Erickson et al., 2015), and UV irradiation (Rastogi et al., 2020) when the stimulus involved is daylight. In line with this hypothesis, stressful conditions such as heat stress would produce similar effects in the activation/inactivation of the chaperone that should be detected as changes in its level of Thr phosphorylation. In fact, in C. reinhardtii, stress induced by high temperature promoted CrBiP dephosphorylation (Díaz-Troya et al., 2011). Therefore, we treated the dark-adapted cells (highly phosphorylated BiP) with temperatures of 21 (cold stress) or $32^{\circ} \mathrm{C}$ (heat stress) and analyzed their response upon light exposure. Cold stress did not produce an observable effect on the Thr phosphorylation level under dark conditions as it remained high (inactive SBiP1), similar to the control $26^{\circ} \mathrm{C}$ condition. As expected, light exposure induced the SBiP1 Thr dephosphorylation response (active SBiP1) in these cells similar to those of the control $26^{\circ} \mathrm{C}$ condition. This suggests that the lower temperature did not have an effect in the normal chaperone function, or at least no detectable changes could be observed under our experimental conditions. We also observed that the lower $21^{\circ} \mathrm{C}$ temperature does not impose a significant stress on the cells under dark conditions, which suggests that the SBiP1 chaperone is maintained inactive. Upon light exposure under these conditions, the cells detect the need to contend with their new environment and SBiP1 Thr dephosphorylation occurs in order to activate the chaperone activity, similar to what was observed at the normal $26^{\circ} \mathrm{C}$ conditions. On the other hand, heat stress under dark conditions did induce Thr dephosphorylation at both long (12 h) and short (30 min) incubation times at $32^{\circ} \mathrm{C}$, suggesting that the normally silenced SBiP1 chaperone activity during the dark phase of the growth cycle is required when a stressful high temperature condition is sensed by the cells. Upon light exposure, the heat-stressed cells displayed an altered phosphorylation response as the SBiP1 Thr phosphorylation level increased but only marginally; namely, to the basal levels normally found in light-exposed control cells. It is unclear why the combination of both heat stress and light would restore, at least in part, SBiP1 Thr phosphorylation. It is well known that in Symbiodiniaceae, heat stress primarily targets proteins that allow the proper function of a light-stimulated mechanism, the photosynthetic machinery (Iglesias-Prieto et al., 1992; Warner et al., 1999; Takahashi et al., 2004). The failure of the photosynthetic apparatus eventually leads to a generalized failure of cell functions that could lead to cell death in both Symbiodiniaceae and their hosts (Venn et al., 2008). In addition, increased mortality and apoptosis as indicated by an increase in caspase 3-like activity in $\mathrm{NO}$ production in $S$. microadriaticum after $24 \mathrm{~h}$ incubation at $32^{\circ} \mathrm{C}$, has been reported (Bouchard et al., 2009). One possibility is that in heat-stressed $S$. microadriaticum under the conditions tested, ROS generation and/or cell death programs, and apoptosis pathways that are induced (Venn et al., 2008), overwhelm the normal signal-transduction pathways involved in perception of stimuli under normal functioning. Under such conditions, the latter would become completely impaired and irreversibly damaged so that they could no longer respond properly to restore normal cellular function. Our data also suggest that regulation of chaperone activity of BiP-like proteins is one of the early responses to heat stress in $S$. microadriaticum.

In conclusion, our results indicate that: a) Thr phosphorylation changes in SBiP1 from $S$. microadriaticum are not due to changes in protein expression; b) posttranslational modification by Thr phosphorylation could be the early response of the cells to activate the SBiP1 chaperone activity upon light stimulation; c) long-term 
incubation at low temperature neither induced changes in the Thr phosphorylation levels of SBiP1, nor altered the dephosphorylation response after light exposure of the cells; d) both short- and long-term incubation at high temperature induced Thr dephosphorylation of SBiP1 suggesting activation of the chaperone activity under stress; and e) the Thr phosphorylation level of SBiP1 was restored to basal levels upon light exposure of the cells suggesting an irreversible alteration of the activation/inactivation responses of the chaperone activity.

\section{Acknowledgements}

We are grateful for the technical help of M.I. Miguel Ángel Gómez-Reali, M.O. Edgar Escalante-Mancera, M.T.I.A. Gustavo Villarreal-Brito, and Dr. Edén MagañaGallegos. We also acknowledge the help of M.C. Laura Celis-Gutiérrez.

\section{Author's contributions}

Raúl Castillo-Medina: Experiments, data acquisition, formal analysis, and reviewing the manuscript. Tania Islas-Flores: Conceptualization and formal analysis, experimental help and reviewing the manuscript. Marco A. Villanueva: Conceptualization, writing, review, and editing. All authors have read and agreed to the published version of the manuscript.

\section{REFERENCES}

Anckar J, Sistonen L (2011) Regulation of HSF1 function in the heat stress response: implications in aging and disease. Annu Rev Biochem 80: 1089-1115. http://doi.org/10.1146/annurev-biochem-060809-095203

Aranda M, Li Y, Liew YJ, Baumgarten S, Simakov O, Wilson MC, Piel J, Ashoor H, Bougouffa S, Bajic VB, Ryu T, Ravasi T, Bayer T, Micklem G, Kim H, Bhak J, LaJeunesse TC, Voolstra CR (2016) Genomes of coral dinoflagellate symbionts highlight evolutionary adaptations conducive to a symbiotic lifestyle. Sci Rep 6: 39734. https://doi.org/10.1038/srep39734

Bradford MM (1976) A rapid and sensitive method for the quantitation of microgram quantities of protein utilizing the principle of proteindye binding. Anal Biochem 72: 248-254. https://doi.org/10.1006/ abio.1976.9999

Bouchard JN, Yamasaki H (2009) Implication of nitric oxide in the heat-stress-induced cell death of the symbiotic alga Symbiodinium microadriaticum. Mar Biol 156: 2209-2220. https://doi.org/10.1007/ s00227-009-1249-3

Castillo-Medina RE, Islas-Flores T, Villanueva MA (2019) Phosphorylation/dephosphorylation response to light stimuli of Symbiodinium proteins: specific light-induced dephosphorylation of an HSP-like $75 \mathrm{kDa}$ protein from S. microadriaticum. PeerJ 7: e7406. http://doi. org/10.7717/peerj.7406

Corpet F (1988) Multiple sequence alignment with hierarchical clustering. Nucl Acids Res 16: 10881-10890. https://doi.org/10.1093/ nar/16.22.10881

Crespo JL (2012) BiP links TOR signaling to ER stress in Chlamydomonas. Plant Signal Behav 7: 273-275. http://doi.org/10.4161/ psb.18767

Díaz-Troya S, Pérez-Pérez ME, Pérez-Martín M, Moes S, Jeno P, Florencio FJ, Crespo JL (2011) Inhibition of protein synthesis by TOR inactivation revealed a conserved regulatory mechanism of the BiP chaperone in Chlamydomonas. Plant Physiol 157: 730-741. https://doi. org/10.1104/pp.111.179861

Erickson E, Wakao S, Niyogi KK (2015) Light stress and photoprotection in Chlamydomonas reinhardtii. Plant J 82: 449-654. https://doi. org/10.1111/tpj.12825

Freiden PJ, Gaut JR, Hendershot LM (1992) Interconvertion of three diferentially modified and assembled forms of BiP. EMBO J 11: $63-70$

Gaut JR (1997) In vivo threonine phosphorylation of immunoglobulin binding protein $(\mathrm{BiP})$ maps to its protein binding domain. Cell Stress Chap 2: 252-262

Gierz SL, Foret S, Leggat W (2017) Transcriptomic analysis of thermally stressed Symbiodinium reveals differential expression of stress and metabolism genes. Front Plant Sci 8: 271. https://doi.org/10.3389/ fpls.2017.00271
Ham H, Woolery AR, Tracy C, Stenesen D, Kramer H, Orth K (2014) Unfolded protein response-regulated drosophila fic (dFic) protein reversibly AMPylates BiP chaperone during endoplasmic reticulum homeostasis. I Biol Chem 289: 36059-36069. http://doi. org/10.1074/jbc.M114.612515

Hendershot LM, Ting J, Lee AS (1988) Identity of the immunoglobulin heavy-chain-binding protein with the 78,000 -dalton glucoseregulated protein and the role of posttranslational modifications in its binding function. Mol Cell Biol 8: 4250-4256. https://doi. org/10.1128/mcb.8.10.4250-4256.1988

Hendershot LM (2004) The ER function BiP is a master regulator of ER function. Mt Sinai J Med. 71: 289-297

Hoegh-Guldberg O, Mumby PJ, Hooten AJ, Steneck RS, Greenfield P, Gomez E, Harvell CD, Sale PF, Edwards AJ, Caldeira K, Knowlton N, Eakin CM, Iglesias-Prieto R, Muthiga N, Bradbury RH, Dubi A, Hatziolos ME (2007) Coral reefs under rapid climate change and ocean acidification. Science 318: 1737-1742. https://doi.org/10.1126/ science.1152509

Iglesias-Prieto R, Matta JL, Robins WA, Trench RK (1992) Photosynthetic response to elevated temperature in the symbiotic dinoflagellate Symbiodinium microadriaticum in culture. Proc Natl Acad Sci US A 89: 10302-10305. https://doi.org/10.1073/pnas.89.21.10302

Islas-Flores T, Pérez-Cervantes E, Nava-Galeana J, Loredo-Guillén M, Guillén G, Villanueva MA (2019) Molecular features and mRNA expression of the Receptor for Activated C Kinase 1 from Symbiodinium microadriaticum ssp. microadriaticum during growth and the light/dark cycle. J Eukaryot Microbiol 66: 254-266. https://doi. org/10.1111/jeu.12667

Kropat J, von Gromoff ED, Müller FW, Beck CF (1995) Heat shock and light activation of a Chlamydomonas HSP70 gene are mediated by independent regulatory pathways. Mol Gen Genet 248: 727-34 http://doi.org/10.1007/BF02191713

Laemmli UK (1970) Cleavage of structural proteins during the assembly of the head of bacteriophage T4. Nature 227: 680-685. https:// doi/org10.1038/227680a0

Lesser MP, Farrell JH (2004) Exposure to solar radiation increases damage to both host tissues and algal symbionts of corals during thermal stress. Coral Reefs 23: 367-377. https://doi.org/10.1007/ s00338-004-0392-z

Lewy TG, Grabowski JM, Bloom ME (2017) BiP: master regulator of the unfolded protein response and crucial factor in flavivirus biology. Yale J Biol Med 90: 291-300

Liepnieks JJ, Light A (1979) The preparation and properties of bovine enterokinase. J Biol Chem 254: 1677-1683. https://doi.org/10.1016/ S0021-9258(17)37826-2

Liu Y, Beyer A, Aebersold R (2016) On the dependency of cellular protein levels on mRNA abundance. Cell 165: https://doi. org/10.1016/j.cell.2016.03.014

Nitika, Porter CM, Truman AW, Truttmann MC (2020) Post-translational modifications of Hsp70 family proteins: Expanding the chaperone code. J Biol Chem 295: 10689-10708. http://doi.org/10.1074/ jbc.REV120.011666

Otero JH, Lizák B, Hendershot LM (2010) Life and death of a BiP substrate. Semin Cell Dev Biol 21: 472-478. http://doi.org/10.1016/j. semcdb.2009.12.008

Pérez-Pérez ME, Couso I, Crespo JL (2017) The TOR signaling network in the model unicellular green alga Chlamydomonas reinhardtii. Biomolecules 7: 54. http://doi.org/10.3390/biom7030054

Preissler S, Ron D (2019) Early events in the endoplasmic reticulum unfolded protein response. Cold Spring Harb Perspect Biol 11: a033894. http://doi.org/10.1101/cshperspect.a033894

Rastogi RP, Madamwar D, Nakamoto H, Incharoensakdi A (2020) Resilience and self-regulation processes of microalgae under UV radiation stress. I Photochem Photobiol C: Photochem Revs 43: 100322. https://doi.org/10.1016/j.jphotochemrev.2019.100322

Satoh M, Nakai A, Sokawa Y, Hirayoshi K, Nagata K (1993) Modulation of the phosphorylation of glucose-regulated protein, GRP78, by transformation and inhibition of glycosylation. Exp Cell Res 205: 76-83 http://doi.org/10.1006/excr.1993.1060

Takahashi S, Nakamura T, Sakamizu M, van Woesik R, Yamasaki H (2004) Repair machinery of symbiotic photosynthesis as the primary target of heat stress for reef-building corals. Plant Cell Physiol 45: 251-255. https://doi.org/10.1093/pcp/pch028

Venn AA, Loram JE, Douglas AE (2008) Photosynthetic symbioses in animals. J Exp Bot 55: 1069-1080. https://doi.org/10.1093/jxb/ erm 328

Villanueva MA (2008) Electrotransfer of proteins in an environmentally friendly methanol-free transfer buffer. Anal Biochem 373: 377-379. https://doi.org/ 10.1016/j.ab.2007.08.007

Warner ME, Fitt WK, Gregory W. Schmidt GW (1999) Damage to photosystem II in symbiotic dinoflagellates: A determinant of coral bleaching, Proc Natl Acad Sci USA 96: 8007-8012; https://doi. org/10.1073/pnas.96.14.8007 